Article

\title{
The Performance Gap in Energy-Efficient Office Buildings: How the Occupants Can Help?
}

\author{
Qadeer Ali ${ }^{1}$, Muhammad Jamaluddin Thaheem ${ }^{2}{ }^{\mathbb{D}}$, Fahim Ullah ${ }^{3, *} \mathbb{C}$ and \\ Samad M. E. Sepasgozar ${ }^{3}$ iD \\ 1 Department of Construction Engineering and Management, National University of Sciences and \\ Technology (NUST), Islamabad 44000, Pakistan; qadeerali.cem5@nit.nust.edu.pk \\ 2 School of Architecture and Built Environment, Deakin University, Geelong, VIC 3220, Australia; \\ jamal.thaheem@deakin.edu.au \\ 3 Faculty of Built Environment, University of New South Wales (UNSW), Kensington Sydney, NSW 2052, \\ Australia; sepas@unsw.edu.au \\ * Correspondence: f.ullah@unsw.edu.au; Tel.: +61-451-72-8281
}

Received: 12 February 2020; Accepted: 10 March 2020; Published: 20 March 2020

check for updates

\begin{abstract}
Rising demand and limited production of electricity are instrumental in spreading the awareness of cautious energy use, leading to the global demand for energy-efficient buildings. This compels the construction industry to smartly design and effectively construct these buildings to ensure energy performance as per design expectations. However, the research tells a different tale: energy-efficient buildings have performance issues. Among several reasons behind the energy performance gap, occupant behavior is critical. The occupant behavior is dynamic and changes over time under formal and informal influences, but the traditional energy simulation programs assume it as static throughout the occupancy. Effective behavioral interventions can lead to optimized energy use. To find out the energy-saving potential based on simulated modified behavior, this study gathers primary building and occupant data from three energy-efficient office buildings in major cities of Pakistan and categorizes the occupants into high, medium, and low energy consumers. Additionally, agent-based modeling simulates the change in occupant behavior under the direct and indirect interventions over a three-year period. Finally, energy savings are quantified to highlight a $25.4 \%$ potential over the simulation period. This is a unique attempt at quantifying the potential impact on energy usage due to behavior modification which will help facility managers to plan and execute necessary interventions and software experts to develop effective tools to model the dynamic usage behavior. This will also help policymakers in devising subtle but effective behavior training strategies to reduce energy usage. Such behavioral retrofitting comes at a much lower cost than the physical or technological retrofit options to achieve the same purpose and this study establishes the foundation for it.
\end{abstract}

Keywords: energy performance gap; occupant behavior; agent-based modeling; energy efficiency; energy savings

\section{Introduction}

Energy and its usage are areas of interest and attract a lot of research attention, resulting in the development of several plans and strategies to address energy-related issues. However, these plans and systems are not straightforward and may present complexities due to their strengths, weaknesses or proper utilization mechanisms [1]. For example, the studies of Azar and Menassa [2] and Lee et al. [1] take into consideration certain limited effects that influence the overall energy use and make the energy optimization and utilization tricky. Similarly, energy usage and optimization have been 
explored from various angles including predictive controls for refrigeration [3], green performance evaluation system for construction site layout [4], performance comparisons of energy systems [5], indoor air quality assessments [6] and others.

The modern ways of living drive substantial energy use inside the buildings. United Nations Energy Program (UN-Energy) reports that buildings consume $30-40 \%$ of the total global energy $[7,8]$. Throughout their lifecycle, buildings consume about $80 \%$ energy when occupied [2]. In the United States alone, commercial buildings consume about $19 \%$ of the total energy [9]. To improve the utility of energy usage, energy-efficient buildings are often presented as a solution. These buildings leverage many efficiency features such as building automation systems (BAS), building management systems (BMS), intelligent control systems, rating procedures, etc. to reduce energy use as much as possible [10].

All of this is absolutely warranted since the state of energy provision and security is alarming in developing countries. For example, Pakistan is facing energy issues including a high energy downtime. The registered shortfall in 2009 was $40 \%$ [11] which grew to be $50 \%$ during the summer of 2012 [12]. The situation remained grim during 2013-2014 as urban areas were facing 10-12 hours of load shedding while in rural areas electricity remained unavailable for 16-18 hours [13]. Although there have been significant improvements on the generation and supply side due to an overall increase in the generation capacity as of 2018-2019, there is still a significant gap between the electricity demand and supply [14]. Owing to substantial energy usage by buildings, they present a potential research area to investigate ways of reducing their energy footprint. The concept of green and energy-efficient buildings is in its infancy in Pakistan [15] and there are very few such projects like FFC Sona Towers in Rawalpindi, MCB Centre in Lahore and Centre Point Tower in Karachi that can be termed as nearly green or energy-efficient buildings. These have been selected for a thorough investigation in the current study.

Despite the development of energy-efficient buildings locally or anywhere else, their reported energy savings are far from design expectations and there is a gap between the predicted and the actual energy use [16-18]. This gap is partly due to the lack of feedback from the building administration to designers, faults in the design or its assumptions, improper modeling tools, build quality, over usage of installed equipment, changes in latent conditions, poor facility management, or behavior of the occupants that is hindering the process of smart building or real estate management [17,19-24]. These causal factors affect energy performance [18] and must be addressed to achieve the desired efficiency. However, not all of them can be addressed conveniently and economically as some demand financial inputs, whereas others require physical intervention in the form of retrofitting of the existing building stock [25]. Among the stated factors, occupant behavior is a soft factor that offers considerable potential for energy savings [2] and may bring significant gains against a minimum input.

Based on this premise, several studies such as Noubissie Tientcheu et al. [26], Jang and Kang [16], Mjörnell et al. [27], and Kaminska [28] show that occupants affect building energy performance with their activities and interactions. Activities like usage of lighting systems and equipment and interactions like meeting and working with other people in the buildings translate into watt-hour or other usage units [29]. Therefore, if an occupant's behavior is positively reinforced towards responsible energy use, significant energy savings can be achieved [30]. To address occupancy issues, many techniques are

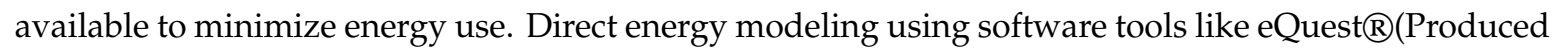
by Southern California Edison, Rosemead, CA 91770, USA), and DesignBuilderß(Produced by Design Builder Software Ltd, Clarendon Court, 1st Floor 54/56 London Rd, Stroud, Gloucs, GL5 2AD, UK) is performed to simulate building energy usage in the early design phase. However, these tools are limited in only allowing variations in occupancy loads and assuming that all occupants will consume the same amount of energy during their occupancy [31,32]. They treat an occupant to have a fixed and uniform behavior. However, the human behavior is dynamic and occupants experience behavior modification during their occupancy either due to inspiration from others or due to the effect of their environment. Research reveals that the predicted energy usage can be improved if the effect of occupants with different energy usage rates is considered [33-35]. It is argued that research must fully integrate the human dimension into the building design and operation processes to reducing 
energy use in buildings while enhancing occupant comfort and productivity [36]. Although certain software tools such as EnergyPlus ${ }^{\mathrm{TM}}$ (Produced by U.S. Department of Energy, 1000 Independence Ave. SW, Washington DC 20585, USA) have been used recently to include different behavioral modules including aspects of occupant behavior, the tool is mainly designed to be used with standard schedules and the essence of behavioral schedules may not be captured in its entirety by it $[37,38]$. Further, the collaboration accuracy of modified models is another aspect to look into when using tools designed for working with general schedules to include behavioral schedules [39].

Therefore, it is important to incorporate the occupant behavior in design so that the design accuracy of energy systems can be improved, resulting in better performance. From literature and analysis of popular energy modeling software, it is found that no commercially available software is capable of accounting for the dynamic energy use patterns. Additionally, these tools are not capable to simulate the behavioral changes caused by the interactions of the occupants with each other and their environment. This limitation results in imprecise usage values, causing surging energy gaps. Technological measures, like the simulation of behavior through exhaustive modeling, can predict energy use over fixed or unlimited occupancy and allow better energy use predictions $[2,34,40]$.

In order to study the impact of occupant behavior, this study addresses the research questions pertinent to the effect of occupant behavior on the performance of energy-efficient office buildings, how occupant behavior evolves over time due to formal and informal influences, and how much energy can be saved by a positive change in occupant behavior. For this purpose, three energy-efficient office buildings and their occupants have been assessed. Using secondary building data from the design and operations phases, the energy gap is identified. Based on the individual occupant data, occupants are categorized as high, medium and low energy consumers. Further, agent-based modeling is performed to simulate the changes in usage patterns due to direct and indirect behavior interventions. The findings are statistically validated to ensure their significance. Based on the results and discussions, the maximum contribution in energy saving is assessed which can become useful for both researchers and practitioners alike. It is expected that the findings of this study will help designers to better predict the actual energy usage and facilitate the building managers to observe the effect of intervention techniques on occupant behavior and their reaction to changes in their environment. The facility managers may also benefit from planning and organizing effective conservation campaigns to ensure better energy performance.

\section{Literature Review}

\subsection{Energy Performance Gap}

The building industry is keenly observing and studying the mismatch between actual and predicted energy performance, generally termed as 'performance gap' $[18,28,40]$. With the rapid growth of building automation, there is a variety of sophisticated equipment that can provide real-time usage data to quantify the energy performance. Although minor variations may be acceptable in prediction and the actual use due to many reasons and uncertainties in the design and construction phases of a building, the research shows this gap is sometimes way out of the acceptable limits, reaching up to 2.5 times the predicted energy usage [16,18]. As occupants and owners expect a lot more from the energy-efficient buildings, the industry is under serious pressure for enhancing its design and execution efficiency. In a broader sense, this gap is wearing down the concept of high-performance buildings in the eyes of the general public.

To overcome this gap, the design, construction, and operation stages must be considered altogether in order to actually deliver an energy-efficient building [41]. Minimizing this gap is crucial for the construction industry and has become a serious impediment in delivering buildings that are adaptive in nature. Adaptive in terms that they can sense and adjust to changes in the environment and occupancy [42]. This brings into focus the facility management which ensures occupant comfort level and building energy performance after its delivery. It is worth noting that only technological measures 
are not sufficient to bridge the performance gap instead a more holistic approach is warranted [41,43]. Similarly, adaptive comfort is another useful domain that has been explored in the research such as Nguyen et al. [44] for southeast Asian regions where it is highlighted that standard effective temperatures should be implemented into building simulation tools to assess thermal comfort without the attention of building classification. However, Manu et al. [45] argue that building types such as mixed-mode or naturally ventilated plays a significant role in occupants behavior where mixed-mode office building occupants are more adaptive than those in air-conditioned offices and less adaptive than those in naturally ventilated offices. Thus, the software developed for energy modeling based on occupant behavior must take this into account as well.

Some deviation between predicted and actual performance is inevitable because of numerical imprecision in simulations, erroneous readings due to poor data gathering, construction dynamics, and probabilistic nature of the estimates and data quality [46]. However, getting its practical understanding has been a primary concern of designers ever since the introduction of energy performance forecast systems, tracing back to the 1960s [47]. Signs of the performance gap as discussed in this research started appearing from the mid-1990s [48] and are still discussed as a core issue $[20,40,49]$. This gap is addressed in a diverse context in different studies, such as the difference between predicted and actual energy performance of a building, including all the complications of sub-systems, occupant behavior, atmospheric conditions, control settings, and others $[5,27,28]$. Tang et al. [5] found that a primary energy saving between $36.7 \%$ to $48 \%$ is attainable by introducing a distributed energy system in buildings. Further, a control strategy combining geothermal and solar energies is recommended due to its good performance and high flexibility. Similarly, Gercek and Arsan [50], while discussing the energy and environmental performance-based decision support process for early design stages of residential buildings under climate change, argue that decisions about solar heat gain and heat transfer coefficients of transparent surfaces on building envelope have the highest impacts on energy and environmental performance in hot-humid climatic conditions. Further, in the context of strategies to improve the energy performance of buildings from the lifecycle perspective, Mirabella et al. [51] argued that the energy performance predictions and measurements should be taken throughout the building lifecycle, including the design phase. However, at this early stage, only limited information including function and scope description is available, whereas the precise details regarding the building services, fittings, and furnishing are rarely known [52].

The energy performance gap is explored at three stages for a mismatch in predicted and actual energy usage by different researchers including the design, construction, and operation stages. In the design stage, the performance issues arise due to miscommunication between designers and clients regarding performance targets of a building as well as within the design team [16,53]. Further, it is quite difficult to fully predict the future functions of the building at this stage. It may be possible that the building is not serving the same purpose for which it was originally conceived due to latent needs $[18,54]$. It is also possible that the building is inadequate or not designed to meet the technical requirements. A few possible reasons are the oversized design of building systems or the lack of proper details at this stage. Even if it is designed as energy-efficient, due to lack of attention in construction processes or sequencing of activities, the building may underperform [55].

In the construction stage, the performance issues arise mainly due to the lack of details and insufficient quality. This may be due to miscommunication between site staff and the design team or non-availability of the specific product to be installed that ultimately results in poor performance of the constructed facility [56]. Finally, the operations stage also contributes towards the energy performance gap, with the occupant behavior being one of the major issues. The occupant behavior is not often the same as considered in the design stage $[57,58]$. Since the estimates of the building system are done based on theoretical and ideal assumptions, the performance gap turns out to be more pronounced due to different operational attitudes. If the occupants fail to use the building as expected, it can be considered as a failure of the whole system $[59,60]$. 


\subsection{Occupant Behavior}

Previous research has investigated the effect of occupant behavior on energy usage $[1,34,35]$. Clevenger and Haymaker [33] studied this effect by considering different energy usage patterns and report that usage can vary by more than $150 \%$. Similarly, Noubissie Tientcheu et al. [26] simulated four office buildings in South Africa and explored the effects of a single occupant's activities, weather conditions, and temperature to show that the load management, temperature, and occupancy management including occupant behavior can result in a saving of $20 \%$ of heating, ventilation, and air-conditioning (HVAC) energy and $29 \%$ of lighting energy. Kaminska [28] utilized heating control algorithms considering the strong influence of individual occupant preferences on the feeling of comfort to reveal that lowering the temperature by $1{ }^{\circ} \mathrm{C}$ results in an energy saving of about $5 \%$. Thus, the occupant behavior drives energy usage and optimization.

It is interesting to note that individual behavior is driven by behavioral attitudes, subjective norms, and perceived behavioral control. Attitude refers to an individual's feeling to perform a specific behavior. Subjective norm refers to an individual's perceived social pressure from others (who are important to him) whether he should indulge in a certain behavior or not. Perceived behavior control refers to the perceived ease or difficulty of conducting the behavior. The theory of planned behavior, which is a classic theoretical model for studying individual behavior [61], considers the relationship between attitudes and behavioral intention but does not take into account the external drivers that influence an individual's attitude and behavioral intention [62]. Chan and Bishop [63] (2013) improved upon this limitation by including moral norms as another integral source of motivation to reinforce positive behavior towards waste recycling. Gao et al. [64] extended the theory of planned behavior by adding the new variables of the descriptive norm and personal moral norm to find that the descriptive norm is the most powerful variable to predict an individual's energy-saving intention. Thus, research on behavioral modification concludes that situational factors most significantly and effectively reinforce the occupant behavior towards energy conservation [65].

Overall, the literature on occupant behavior can be classified into three different groups: lighting preference, office equipment usage, and occupant schedules. In the first group, the occupant behavior is studied only by lighting patterns and modifications based on outside luminosity. The results show that the occupants who rely more on daylighting can save more than $40 \%$ energy than those relying on artificial lighting systems [29]. The second group is about the usage of office equipment in commercial buildings. In the United States, over $50 \%$ of the office equipment is left switched on during non-working hours [66]. Sanchez et al. [67] analyzed the type and usage of plug loads in a variety of office buildings, showing that $59 \%$ of desktop computers, $45 \%$ copiers, and $41 \%$ scanners and printers remain switched on during non-working hours. The third group of studies mainly focuses on the effect of occupant schedules on total energy usage. In this regard, a single-person office model was developed by Wang et al. [68] to forecast the daily attendance of the occupants. All these studies underline that occupants have a tendency to excessive energy usage which if saved can result in significant performance increase, sustainability gains, and financial saving. Several methods and tools are available to help in reducing energy use primarily requiring a behavior modification of the occupants to adopt energy-saving habits $[28,30]$. The most common techniques that are effective in changing the behavior are (1) social marketing or energy conservation training and workshops, (2) information feedback, and (3) peer-to-peer influence [30,69-71]. These techniques can bring significant change if applied properly during the building occupancy [71]. However, usage habits are dynamic in nature and it is difficult to predict or preserve them during the design stage. Therefore, a holistic approach needs to consider the entire lifecycle [72].

\subsection{Behavior Simulation Through Agent-Based Modeling}

The occupant behavior is generally non-linear and complex, and hence it can be studied from a complex systems perspective [73]. Several techniques are available, among which System Dynamics and Agent-based Modeling (ABM) are commonly used to model such a complex system [74-78]. 
$\mathrm{ABM}$ is an extensively used technique that simulates the interaction of agents with other agents and their environment [79]. Its strength lies in its capability to improve the simulation at any stage against minor modifications in the system. This allows ABM to develop intelligent control systems [80]. One of the contributions of ABM is to develop an approach for energy-saving and its estimation in buildings [2]. The key benefit is its ability to cover those drawbacks which are not addressed by the commercially available energy modeling software such that it effectively addresses the existing uncertainties. Software such as eQuest only allows variations in hourly occupancy loads as they assume that occupants have the same pattern of energy use and it is constant over the building lifecycle $[31,32,81]$. ABM represents the environment in a natural way in context with the occupants and acts in accordance with their behavior. Some of the benefits of ABM are (1) an agent in ABM has the ability to think intelligently by observing its environment and adopting the changes to achieve certain goals, (2) "if-then" condition is extensively used that allows the agent to learn and change its behavior through experience, (3) when developed carefully, the results will be very useful for the system as a whole, and (4) it can capture the natural phenomenon which leads to a wider acceptance of the modeling approach [1].

ABM has been used for energy simulation in building energy research with case studies of the emergency department of a health care facility [82]. The results were used to optimize the size of the HVAC system to avoid excessive airflow and achieving energy saving. This simulation model exhibits that the required size of the ventilation system may vary by $43 \%$ if the building occupancy is modeled properly. Similarly, another study by Erickson et al. [55] reveals that by accounting for the occupancy pattern during energy estimation, not only HVAC loading can be reduced by $14 \%$ but also the oversizing problem can be reduced, resulting in initial cost saving. Azar and Menassa [2] expanded the scope of ABM by focusing on the behavioral impact of the occupants on total energy use by considering their word of mouth influence and energy conservation training. Their study concluded that $25.2 \%$ of the energy savings can be achieved if more control is given to the occupants. The need for $\mathrm{ABM}$ is further advocated due to the limited capability of currently available estimation programs which only account for lighting and HVAC related modeling. However, dynamic occupant behavior is not a key input variable in these modeling tools [31,32]. For the sake of improved estimation, it is very important to consider the dynamic impact of occupant behavior on energy usage [34,35,40].

Owing to this, the current study emphasizes on occupant behavior and their role in energy savings. An agent-based model is developed to simulate the behavior and interactional engagements over time. The findings hint towards a reasonably significant performance deficiency of available commercial software that can be utilized to improve upon the state of art, allowing building stakeholders for better energy management.

\section{Materials and Methods}

This study is carried out in five steps: (1) identification of different energy behaviors, (2) identification and selection of behavior modification factors, (3) data collection from designers, facility managers, and occupants of the case buildings, (4) development and simulation of the ABM model, and (5) analysis and conclusions.

\subsection{Identification of Energy Usage Behaviors}

The overall occupant energy usage behavior is dynamic and uncertain. It is because energy usage can vary significantly when occupants with different usage patterns are taken into consideration [35]. Based on the studies of Guthridge [83], and Azar and Menassa [2], building occupants can be categorized into high energy consumer (HEC), medium energy consumer (MEC) and low energy consumer (LEC). The major difference between these categories is their pattern of energy usage. HEC represents the occupants with excessive energy use, whereas the MEC occupants make very little effort or are in the process of making up their mind for energy-saving. They represent an average consumer. LEC occupants use energy very efficiently by making a conscious effort towards energy 
saving. To appreciate the difference between these categories, it is important to understand the energy use in terms of building systems such as air conditioning, lighting, use of equipment, natural ventilation, etc.

Different studies have explored these building energy systems such as Bourgeois et al. [29] explained how switching patterns and luminosity requirement can be varied in commercial buildings and their possible effects, including the effect of manual and automatic lighting. Sanchez et al. [67] and Webber et al. [66] studied the effect of computers and equipment on energy as per their use patterns in office buildings during working and non-working hours. Davis and Nutter [84] and Wong et al. [10] studied the effects of occupant attendance in office buildings on energy use. These research efforts are attempts to better understand the building systems which ultimately helps in understanding the behavior.

Accordingly, the assumptions made in the current study are (1) HEC occupants do not bother about energy usage; they leave their computers, lights, and HVAC turned on during the non-working hours. MEC occupants turn their computers off before they leave their office but not during breaks. They do not completely rely on natural daylight and use some artificial lighting. Further, they use HVAC systems by keeping the thermostat at low levels. LEC occupants turn off their computers when they leave their office for the day as well as during breaks. They utilize natural daylight properly and use the HVAC only when needed. Table 1 summarizes all these assumptions in terms of their usage.

Table 1. Behavior assumptions according to the use of energy systems.

\begin{tabular}{ccccc}
\hline Behavior & Artificial Light Use & Daylight Use & Equipment Use & HVAC Use \\
\hline HEC & High & No use & High & High \\
\hline MEC & Medium & No use & Medium & Medium \\
\hline LEC & Low & High & Low & Low \\
\hline
\end{tabular}

\subsection{Identification and Selection of Behavior Modification Factors}

Behavior modification is subject to several factors such as the environment where people live or work, routines, working patterns, peer-to-peer influence, training, workshops, etc. In the current study, the factors used to determine the change in behavior towards energy usage are divided into two major categories: (1) formal category which consists of energy events, signboards, and advertisements and (2) informal category which consists of peer-to-peer influence, and acts of senior management. The energy events in the formal category include training sessions or workshops that are aimed at sharing information about responsible usage practices and ways to save energy without compromising comfort. These events could be routinely arranged by the building administration or facility managers. However, in the current study, only annual energy events are considered and simulated. These events should be attended by all building occupants because research shows that they influence the occupants to adopt responsible usage behavior. These awareness events cause some HEC occupants to convert to MEC and some MEC to LEC [83]. The advertisement in the form of commercials over electronic media or signboards strategically placed at prominent points also affects human behavior. Different advertisements by public agencies or equipment manufacturers can help realize energy savings as they create awareness of energy-saving habits [85].

In the informal category, the peer-to-peer effect is prominent as it represents the influence of people through interaction with each other. Thus, while sharing common office space, each occupant influences the others by their habits leading to replication of each other's actions. For example, in a combined space of four people, if two are energy savers (LEC) and two consume excessive energy (HEC), there is a possibility that the LEC influence HEC, which helps them to adopt energy-saving habits or vice versa. This kind of interaction has been studied in marketing where the research shows that the buyer of a product becomes an adopter and in turn influences others, causing a snowball phenomenon [86]. Similarly, the current study models occupant behavior by assuming that the three 
classes of users influence each other in the context of energy usage. The occupants are assumed to be adopters who embrace the behavior of others while working in the same environment. Further, the act of senior members may influence other members of the team to develop their energy-saving habits. The leadership role vested into senior members allows them to influence others to adopt energy-saving behavior routinely displayed by them. For example, a senior person turning off their computer and task lights before leaving their table may motivate the other members to adopt this habit, ultimately helping them to become LEC.

\subsection{Data Collection}

For the collection of data, three energy-efficient buildings were selected in three major cities of Pakistan. The behavioral data is collected through a questionnaire survey and interviews from the occupants to assess their usage behavior and categorize accordingly. The questionnaire, as given in Appendix A, contained six sections as per the building systems, in which the first two sections consisted of questions related to personal information and energy efficiency awareness. The remaining four sections inquired about the user preferences of HVAC, artificial lighting, daylighting, and various office equipment such as computers, printers, scanners, etc. The questions were designed to avoid confirmation bias by inquiring about the usage habits directly and indirectly. For example, on one hand, the occupants were directly inquired about their energy efficiency priorities through questions like "How well-informed do you feel about using the energy-saving design features in your building?" or "How would you describe your approach to reducing energy in your building?". On the other hand, they were asked to expand upon their usage behavior through questions like "What you usually do with your computer when you leave your office for a short break or for a short meeting?" or "If you have windows in your office, for how long do you use daylight approximately?". Through such a counterchecking design, the questionnaire helped to assess the pattern of activities performed by the occupants in their daily routine.

To ensure the representativeness of the survey, the statistical rationale was established. According to Dillman [87], the minimum sample size for a questionnaire survey with a $90 \%$ confidence interval is 83 . To ensure better representativeness and significance, responses were collected from 101 mixed-gender and mixed-age occupants of three buildings, as given in Table 2. The total occupants of these three buildings were 476, among whom 200 were randomly asked to be part of the study to avoid bias. The respondents were engaged in the data collection process during entry to the office, lunch breaks and casual break times during the day after approvals from the upper management. Additionally, the operational data of energy usage was collected from building management and the predicted energy usage data from particular building designers.

Table 2. Details of selected buildings.

\begin{tabular}{cccccc}
\hline Code & Name & Area (Sq. Ft.) & Location & $\begin{array}{c}\text { Number of } \\
\text { Responses }\end{array}$ & $\begin{array}{c}\text { Total } \\
\text { Occupants }\end{array}$ \\
\hline Building 1 & FFC Sona Tower & 316,000 & Rawalpindi & 32 & 176 \\
\hline Building 2 & Centre Point Tower & 202,732 & Karachi & 26 & 157 \\
\hline Building 3 & MCB Centre & 187,000 & Lahore & 43 & 143 \\
\hline
\end{tabular}

\subsection{Agent-Based Simulation Model}

Based on the collected data and reviewed literature, an ABM simulation model is developed in AnyLogic7®(Produced by AnyLogic North America, Oakbrook Terrace Tower, 1 Tower Ln, Suite 2655, Oakbrook Terrace, IL 60181, USA) environment. This software is extensively used to build agent-based models [88]. In the developed model, multiple influence cases are developed. For example, in one case, an HEC occupant influences the MEC and LEC to convert to HEC. In another case, the MEC occupant 
influences LEC and HEC to convert to MEC. In the final case, the LEC occupant influences MEC and HEC to convert to LEC, as shown in Figure 1.

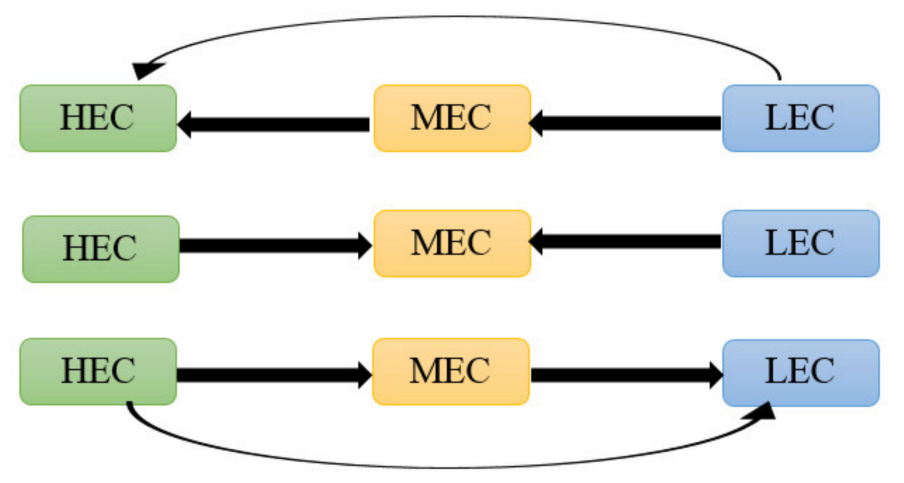

Figure 1. Behavior modification cases.

The building occupants are represented by agents in the model defined by different characteristics that describe the ways of their interaction with the environment and each other and allow them to bring change in their characteristics. This is an iterative process in which the agents continue to interact with each other and change their characteristics. If the change is from HEC to LEC, it is a positive change which ultimately leads to low energy usage and greater energy savings and vice versa. The model flowchart shown in Figure 2 simulates the change of behavior from one category to another with the ultimate agenda of adopting positive behavior until the last iteration of the simulation.

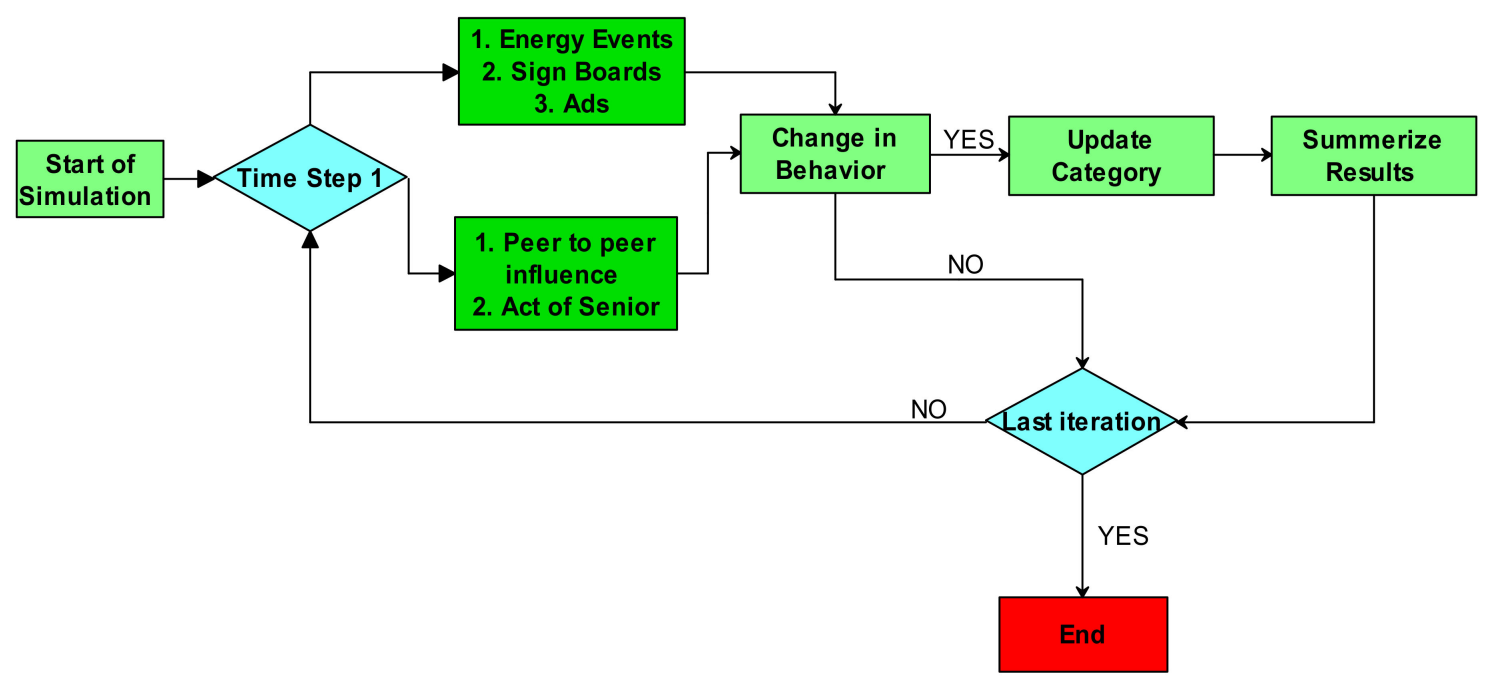

Figure 2. Simulation model flowchart.

The model simulates the interactions of agents and their behavior for a period of three years. A longer simulation period is selected because it allows enough time to observe the long-term effects of permanent behavior modification [89]. The behavior change depends upon two things: the number of occupants in each category and the level of influence on each other. In other words, it is how much each category of occupants affects the other categories to change their behavior while sharing the same environment. The level of influence for LEC is assumed as $2 \% /$ person/month which means that every person in LEC has a capacity to convert any other occupant to change its category by $2 \%$ every month. Accordingly, if the value of the level of influence of one category is higher, it means it compels more to others for changing their behavior.

At the start of the simulation, the model analyzes the results of formal and informal methods simultaneously. In the formal category, values of influence of energy events, signboards, 
and advertisements are fed into the model and simulated by coupling with the level of influence of each category. If the behavior is modified, the model updates the categories and stores the new number of HEC, MEC, and LEC occupants for the next iteration. In the next step, the model summarizes results and checks the category of occupants, and the results are displayed showing how many occupants have changed their behavior and converted to other categories. This process is repeated until the total simulation time has reached. The results are displayed in the form of graphs and time statecharts showing how many occupants have changed their behavior and the influence it brings over the total energy usage.

For the current study, the sample is modeled in three behavioral categories of HEC, MEC, and LEC as per their self-reported usage habits. The hierarchy of communication and the way occupants change their behavior is defined while developing the model. Figure 3 illustrates the model state chart in which the behavioral categories are joined with the help of transitions.

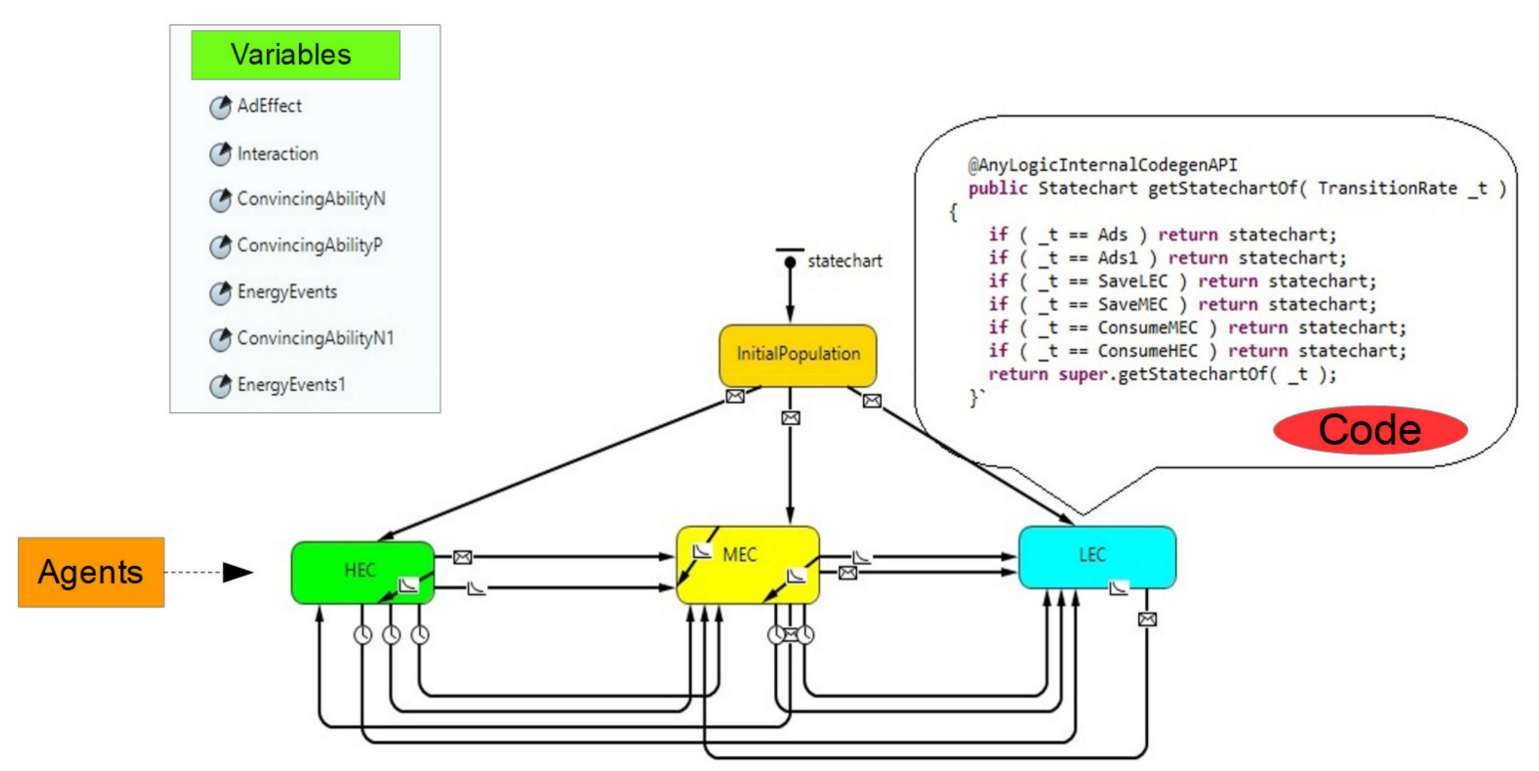

Figure 3. Model statechart showing the interactions of agents, the variables and the input code. Note: HEC means High Energy Consumers, MEC means Medium Energy Consumers, and LEC means Low Energy Consumers.

These transitions are also used to express the path to add or subtract the number of occupants in each category for an event while simulating the model. The model is programmed in Java for both transitions as well as behavior categories of the statechart. The parameters which affect the behavior are defined with values taken from different studies as shown in Table 3, where all values are provided along with their definitions. For example, the effect of advertisements is taken as 0.01 which exhibits that $1 \%$ of the total population can be affected per day [90]. These parameters may not be valid for and applicable to all cultures. Thus, it is necessary to have culture-specific values and inputs while developing codes and tools for occupant behavior modeling. However, for the current study due to the absence of parameters and relevant studies in the context of Pakistan, values and parameters are adopted from relevant global studies. At the start of the simulation, the value of each parameter can be changed, and users can define it according to their requirements depending upon the nature of the environment under study. Further, the selected parameters are the ones that only modify the occupant behavior. The data is obtained from occupants regardless of their level of education and social status. Factors like a sudden change in weather and energy-saving incentives also modify the behavior but such modification is intermittent and temporary and does not affect the overall energy usage of a building. Hence, such temporary factors are excluded 
Table 3. Parameters and their values used in the model.

\begin{tabular}{ccc}
\hline Parameter & Value & Definition \\
\hline Level of Influence & $2 \% /$ Person/month & $\begin{array}{c}\text { Each occupant has a } \% \text { chance of effectively } \\
\text { converting another occupant in its category } \\
\text { each month [85]. }\end{array}$ \\
\hline Energy events & 1 per year & $\begin{array}{c}\text { Energy events are arranged by the building } \\
\text { administration once per year [2]. }\end{array}$ \\
\hline Effect of advertisements & $50 \%$ & $\begin{array}{c}\text { Energy events cause about half of the occupants } \\
\text { who attend to change their category [2]. }\end{array}$ \\
\hline Interaction & $1 \%$ & $\begin{array}{c}1 \% \text { of the total population is affected by } \\
\text { advertisements per day [90]. }\end{array}$ \\
\hline
\end{tabular}

One of the significant challenges, as well as quality checks for simulation-based studies, is the validation of the simulation model. Of the several possible options, the current study expanded upon the tradition of Azar and Menassa [2] by integrating face validity with the empirical checks. In doing so, the input data have been obtained from reliable sources like Pakistan Electric Power Company (PEPCO) [67], ASHRAE 90.1 [68], USGBC, and Energy Star. Additionally, the behavior influence inputs are the same as available in the published research. Though it can be argued that different socio-cultural backgrounds and drivers might create significant differences in occupant behavior and their capacity to accept influence, and we accept this criticism as valid, the limitation on capacity and resources did not allow us to expand this study into covering such aspects. Future research will involve actual data collection to test and verify the assumptions made about occupancy and behavior characteristics in the current study.

\section{Results and Discussion}

\subsection{Energy Gap Analysis}

Following the structured methodology, the first objective of finding the gap between the expected and actual energy performance is achieved by collecting data from designers and building managers as shown in Table 4. The average daily usage (both expected and actual) has been escalated to monthly figures by considering 22 working days (rounding off 21.62) in a month. The value for expected usage has been provided by the building designers based on the design parameters and the equipment considered during the design phase of the building whereas the value for actual usage is obtained from building managers and their teams based on the actual utilization of energy according to the received energy bills.

Table 4. The performance gap between predicted and actual energy use.

\begin{tabular}{ccccccc}
\hline Code & $\begin{array}{c}\text { Designed/ } \\
\text { Expected Usage } \\
\text { (kWh/day) }\end{array}$ & $\begin{array}{c}\text { Actual } \\
\text { Usage } \\
\text { (kWh/day) }\end{array}$ & $\begin{array}{c}\text { Designed/ } \\
\text { Expected Usage } \\
\text { (kWh/month) }\end{array}$ & $\begin{array}{c}\text { Actual } \\
\text { Usage } \\
\text { (kWh/month) }\end{array}$ & Difference & $\begin{array}{c}\text { Performance } \\
\text { Gap }\end{array}$ \\
\hline Building 1 & 750 & 900 & 16,500 & 19,800 & 3300 & $16.7 \%$ \\
\hline Building 2 & 600 & 700 & 13,200 & 15,400 & 2200 & $14.3 \%$ \\
\hline Building 3 & 550 & 650 & 12,100 & 14,300 & 2200 & $15.4 \%$ \\
\hline
\end{tabular}

Analyzing the monthly usage data, it is found that a considerable gap exists between the predicted and actual energy. Building 1 has $16.7 \%$ more energy usage than predicted at the design stage. Similarly, $14.3 \%$ and $15.4 \%$ are energy gaps for Building 2 and Building 3, respectively, giving an average gap of $15.5 \%$. As a result, it is logical to assume that this gap is due to imprecise simulation, building 
design, equipment selection, construction quality, or occupant behavior. Apparently, it is not possible to attribute this gap to any single cause, rather a combination of these causes results in such a higher performance gap.

\subsection{Existing Usage Behavior Analysis}

In order to achieve another objective of categorizing the sampled occupants from case buildings into various energy usage categories, usage habits were inquired through the questionnaire survey. The self-reported energy usage behavior is extracted for performing further analysis which utilizes average energy usage by commonly available equipment in office buildings. The standard usage values are taken from different sources including PEPCO [67], ASHRAE 90.1 [68], USGBC, and Energy Star as shown in Table 5 .

These usage values are used in order to rank the equipment category based on energy usage per square foot area using Equation (1) or per hour using Equation (2). The value of $61 \mathrm{ft}^{2}$ is sourced from Time Saver Standards [91] which is the average area of office spaces found in buildings under study.

$$
\begin{gathered}
\text { Load }=\text { Loads (per Sq. Ft.) *61 Sq. Ft. } \\
\text { Load }=\text { Loads }(W) * \text { Hourly usage }
\end{gathered}
$$

Table 5. Equipment standard energy usage values.

\begin{tabular}{ccc}
\hline Equipment & Energy Usage (Per Unit of Equipment or Area) & Source \\
\hline HVAC/AC & $1400-1600 \mathrm{~W}$ & [92], USGBC \\
\hline Computer & $200 \mathrm{~W}$ & [92], USGBC \\
\hline Printer & $250 \mathrm{~W}$ & USGBC and Energy Star \\
\hline Scanner & $150 \mathrm{~W}$ & USGBC and Energy Star \\
\hline Desk fan & $70 \mathrm{~W}$ & [92] \\
\hline Table lamp & $60 \mathrm{~W}$ & [92], USGBC \\
\hline Energy saver & $22 \mathrm{~W}$ & [93] \\
\hline Daylight & $0.98 \mathrm{~W} / \mathrm{ft} 2$ & [93] \\
\hline Equipment load & $0.36 \mathrm{~W} / \mathrm{ft} 2$ &
\end{tabular}

These calculations are performed to find the weight of each equipment category during working and non-working hours, as shown in Table 6. The hourly usage values are based on the typical office schedule of 9 am- $6 \mathrm{pm}$. Depending upon the types of equipment and their hourly usage, their relative weight in overall usage is calculated. The HVAC systems consume more energy than all other equipment, thus a weight of 0.394. This is in line with the findings of Masoso and Grobler [94] who figured out an average HVAC usage of $72 \%$ for hot and dry climates of Botswana and South Africa. Secondly, despite their low hourly usage, desktop computers consume a lot of energy as compared to other equipment due to their extensive use throughout the day. On the other hand, the lighting system found in these buildings is BMS controlled, which implies that it operates on a fixed schedule that varies from building to building and with the occupant schedule. In the case of the artificial lighting system, BMS is programmed to switch them on during working hours only. So, there is no possibility of lights remaining switched on during non-working hours. However, the downside of these automatic lighting systems is that the occupants have no control over lights, thus eliminating the impact of their behavior in energy saving. 
Table 6. Ranking of equipment energy usage based on energy usage.

\begin{tabular}{cccccc}
\hline Equipment & Time of Use & Watt/hr & Hourly Use & Energy Usage & Weight \\
\hline HVAC/AC & Working hours & 1500 & 9 & 13,500 & 0.394 \\
\hline Computer & Non-working hours & 200 & 15 & 3000 & 0.088 \\
\hline Printer & All day & 250 & 9 & 2250 & 0.066 \\
\hline Computer & Working hours & 200 & 9 & 1800 & 0.053 \\
\hline AC & Meetings & 1500 & 1 & 1500 & 0.044 \\
\hline Scanner & Non-working hours & 150 & 9 & 1350 & 0.039 \\
\hline Lights & Non-working hours & 22 & 15 & 330 & 0.010 \\
\hline Desk fan & When needed & 70 & 4 & 280 & 0.008 \\
\hline Desk lamp & When needed & 60 & 4 & 240 & 0.007 \\
\hline Computer & Meetings & 200 & 1 & 200 & 0.006 \\
\hline Lights & Working hours & 22 & 9 & 198 & 0.006 \\
\hline Daylight & When available & 60 & 2 & 120 & 0.004 \\
\hline Windows & When needed & 22 & 4 & 88 & 0.003 \\
\hline Lighting & Meetings & 22 & 1 & 22 & 0.001 \\
\hline
\end{tabular}

The use of daylighting has the potential to save a large amount of energy as it provides an appealing environment and a pleasant workspace that can increase both performance and productivity [95]. Field studies and simulation analysis show that daylighting has the potential to save energy from 30-70\% [96-98]. The data obtained from the case buildings reveals that most of the occupants complain of not having enough daylight which can be associated with their working position, office layout or operating style of blinds and windows. After getting the weight of each equipment, an individual score is calculated for each respondent using Equation (3), where $W i$ is the weight of equipment and Ki is the individual use score of equipment as reported by respondents.

$$
\text { Individual Score }=\sum_{i=1}^{n} W_{i} \times K_{i}
$$

The values of the individual score range between 2.96-6.7 which are equally divided into 3 ranges, as shown in Table 7, along with the frequency of respondents in the given category. The higher values show the score of HEC and the lower values represent LEC. Accordingly, 24 occupants are categorized as LEC, 54 as MEC, and 23 as HEC, giving a seemingly normal distribution where most of the respondents are in the middle.

Table 7. Respondent distribution as per energy usage.

\begin{tabular}{ccc}
\hline Category & Range & Frequency \\
\hline LEC & $2.96-4.2$ & 24 \\
\hline MEC & $4.2-5.5$ & 54 \\
\hline HEC & $5.5-6.7$ & 23 \\
\hline
\end{tabular}

\subsection{Agent-Based Modeling (ABM) Simulation Analysis}

The simulation starts with initial values of LEC, MEC, and HEC as per Table 7 and shows the effect of all parameters on occupants. If there is a change in the category of a consumer, it updates the occupant category and jumps to another time interval for the next iteration. Figure 4 shows the results of simulation over a 3-year period. Initially, the effects of advertisements and interaction in converting usage behavior are visible. Though advertisements seem successful in preserving LEC, 
the peer-to-peer influence of HEC is negatively effecting the MEC in the form of a sustained increase in HEC and a decrease in MEC. To curb this energy inefficient behavior, the first energy event is simulated after 12 months. It seems without an energy event or any training, people are influenced by irresponsible usage behavior of HEC. This influential effect is highly noticeable in MEC who are adopting bad usage habits. It is possible that occupants are unaware of energy-saving techniques or are too busy to consider it, hence becoming careless towards energy conservation. Further, seeing senior influential colleagues as HEC may also trigger such bad behaviors.

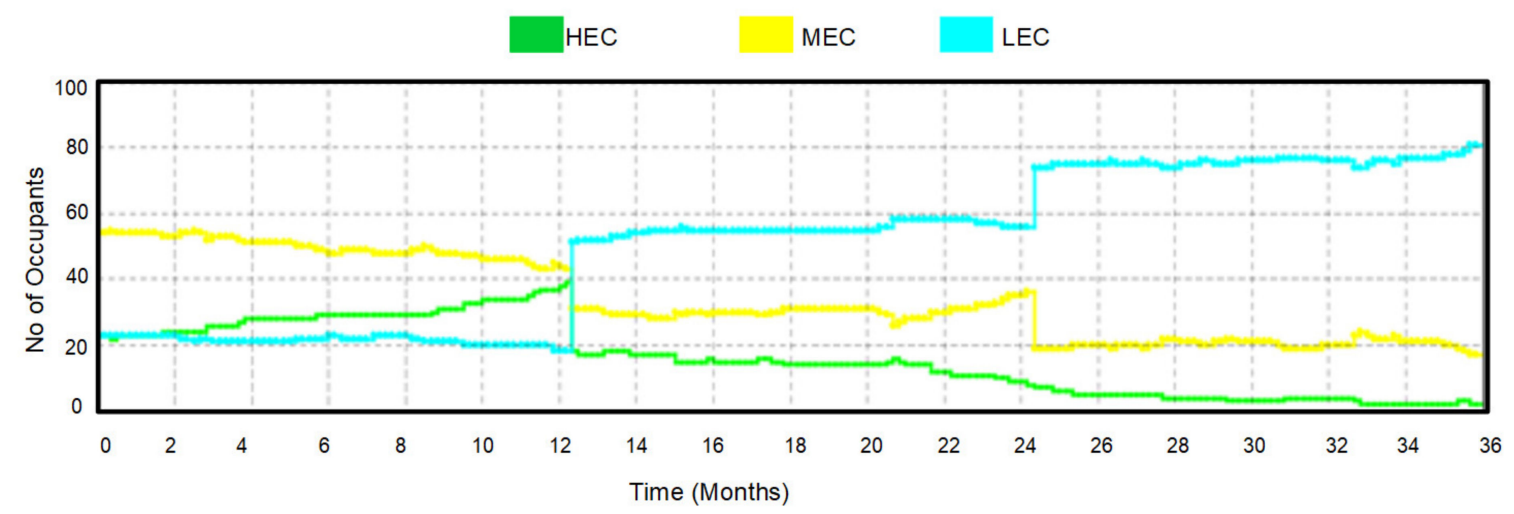

Figure 4. Occupants behavior change over time.

Nevertheless, it is encouraging that LEC occupants sustain their behavior over a longer period because of having adequate knowledge and ingrained habits of energy-saving and sustainability. To spread the knowledge of energy saving, energy events are arranged. The efficiency of these events is set to $50 \%$ which means that after attending the event, half of the occupants will be influenced to change their usage behavior. Accordingly, the first energy event causes a major change in behavior with an increase in the number of LECs either from MEC or directly from HEC pointing to their effectiveness. The number of HEC has drastically decreased due to conversion into other categories. As evident from Figure 4, the number of MEC occupants is in the middle as opposed to being at the top before the energy event. So, after the first energy event, 19 HEC, 32 MEC, and 50 LEC occupants are carried forward to the next stage of simulation.

Between 12-24 months, the behavior sustaining capability of occupants is quite evident. It is probably because energy events only mean to spread awareness of the benefits of energy-saving, not impose energy-saving habits on the occupants. Imposing will be counterproductive because when something is imposed, people tend to retaliate. Therefore, such events should only encourage the ideas, highlight the importance, and raise awareness among the occupants. The behavioral change and subsequent adoption resulting from such sessions should be at the disposal of the occupants. Such self-realized behavioral changes are usually long term and more sustainable than the ones imposed on the occupants [89]. With minor changes, occupants sustain their behavior throughout the year. The next energy event is organized at the end of 24 months which causes a high change in the number of MEC converting to LEC. Figure 5 displays the density of the occupants who experience the behavior modification from the beginning of the simulation to the end after the 36 months period. As a result, most of the occupants have changed their category and are converted into LEC. At the end of the simulation, the number of LEC is 81, MEC is 16 , while HEC is only 4. 


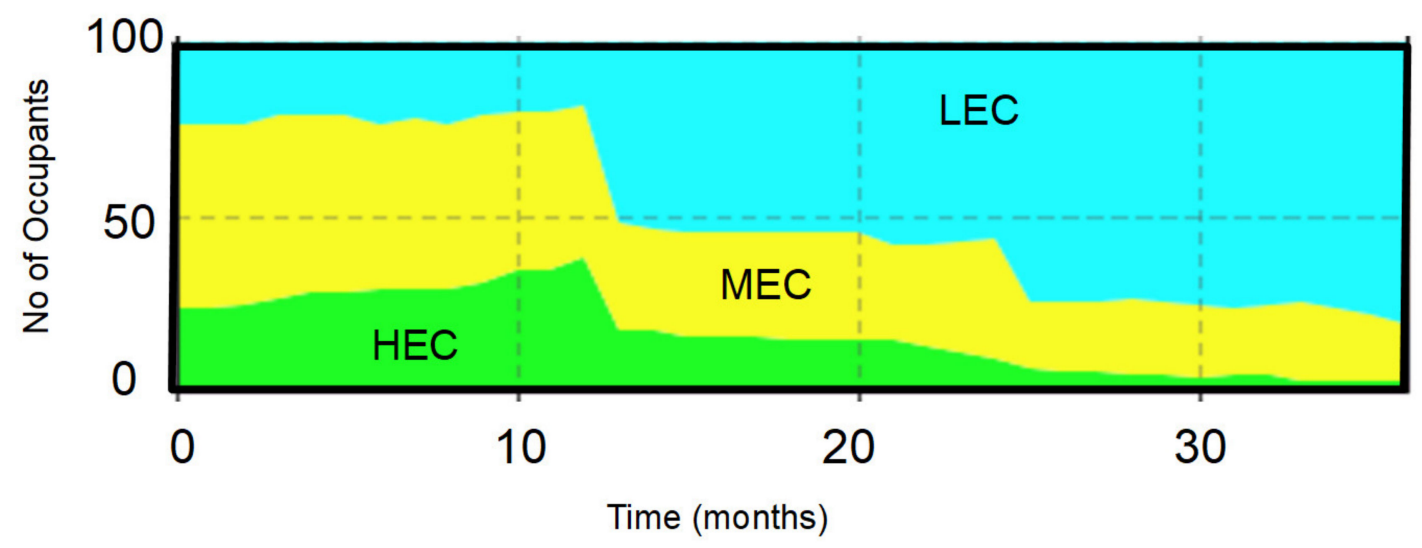

Figure 5. The density of the occupants in each category over time.

The evolution of occupants in their energy use behavior is sensitive to the input parameters given in Table 3. A sensitivity analysis reports that the most significant parameter is energy events due to a considerable efficiency of $50 \%$. Other modification techniques, though garnering more lasting and sustainable results, have much lower efficiency and thus the overall evolution is much less sensitive to them.

\subsection{Energy-Saving Estimation Due to Behavior Modification}

In order to show the significance of the results obtained from the simulation model and putting them in perspective, possible overall energy saving must be estimated. For this purpose, the amount of energy consumed by an occupant should be known. Usually, published usage is an average of the usage per capita and may only be roughly attributed to MEC. In order to know the hypothesized non-linear difference between MEC and the other consumer behaviors, the data is almost nonexistent. Therefore, heuristics are applied to get upper (HEC) and lower (LEC) ranges of an average consumer (MEC). To establish these values, the two most commonly used electricity usage equipment are considered i.e. lighting and air conditioning (AC). Currently, three different types of equipment exist for both categories in the market based on their energy demand. For example, in the case of lights, fluorescent, compact fluorescent, and LED lights are considered. Similarly, window AC, split units, and inverters are considered for air conditioning. So, based on their electricity usage, all of them are categorized as high, medium, and low energy consumers. A comparison of these systems and their percentage increase in usage is given in Table 8.

Table 8. Comparison of equipment based on electricity usage.

\begin{tabular}{cccccc}
\hline Equipment & Low & Medium & High & $\begin{array}{c}\text { Percentage Increase } \\
\text { from Low to Medium }\end{array}$ & $\begin{array}{c}\text { Percentage Increase } \\
\text { from Medium to High }\end{array}$ \\
\hline Lights (Watts) & $10 \mathrm{~W}$ & $14 \mathrm{~W}$ & $60 \mathrm{~W}$ & 28.6 & 76.7 \\
\hline AC (Watts) & $1490 \mathrm{~W}$ & $1566 \mathrm{~W}$ & $1676 \mathrm{~W}$ & 4.9 & 6.6 \\
\hline & & & Average & 16.7 & 41.6 \\
\hline
\end{tabular}

The medium value is considered as the base value, while the rest of the calculations are made accordingly. In the case of the lighting system, the percentage increase form low to medium and medium to high is quite extraordinary. The underlining reason is that technology has significantly improved from fluorescent tube lights to LED lamps. In contrast, despite improvements in technology, the difference is much lower in the case of air conditioners. This is because electricity usage is already too high and improvement in technology can only marginally reduce it. Although estimations based on these statistics can be challenged owing to smaller samples, larger standard deviation, and major differences between the usage of each system, it is assumed that these heuristics offer a logical value 
for the non-linear usage behaviors. Further, three usage scenarios as explained in Table 1 have been considered in order to decide about the category of the occupants. Based on these, the usage rates are estimated as given in Table 9.

Table 9. Behavior-wise energy usage.

\begin{tabular}{|c|c|c|c|c|c|c|c|c|c|}
\hline \multirow{2}{*}{ Equipment } & \multicolumn{3}{|c|}{ LEC } & \multicolumn{3}{|c|}{ MEC } & \multicolumn{3}{|c|}{ HEC } \\
\hline & Hours & Watt & Total & hours & Watt & Total & Hours & Watt & Total \\
\hline Computer & 8 & 200 & 1600 & 9 & 200 & 1800 & 15 & 200 & 3000 \\
\hline HVAC & 4 & 1500 & 6000 & 6 & 1500 & 9000 & 9 & 1500 & 13,500 \\
\hline \multirow[t]{2}{*}{ Lights } & 1 & 22 & 22 & 2 & 22 & 44 & 2 & 22 & 44 \\
\hline & & Total & 7622 & & Total & 10,844 & & Total & 16,544 \\
\hline \multicolumn{3}{|c|}{ Usage rates $(\mathrm{kWh})$} & 1524.4 & & & 2168.8 & & & 3308.8 \\
\hline
\end{tabular}

The per capita energy usage in Pakistan for the year 2018 is reported to be $522 \mathrm{kWh}$ [99] which can be considered as a standard value for MEC as it reflects the national average. Compared to developed countries such as the United States with 11,851 kWh, the UK with $4749 \mathrm{kWh}$, and Australia with 9774 $\mathrm{kWh}$ for the same year [100], the average usage in Pakistan is much lower due to power shortage and lower economic conditions of its people. Thus, it falls in the same group as Sri Lanka with $561 \mathrm{kWh}$, and North Korea with $547 \mathrm{kWh}$ [101]. As hypothesized previously, MEC is not equidistant from LEC and HEC. As per the findings reproduced in Table 8, it is evident that the average percentage increase from low to medium and medium to high is different from LEC to MEC and MEC to HEC, as shown in Figure 6.

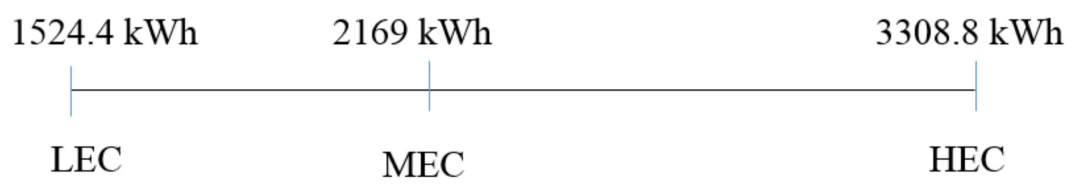

Figure 6. Quantitative distribution of energy usage behaviors.

This implies that HEC occupants are consuming far more amount of energy than that saved by the LEC occupants. Thus, a change of behavior from MEC to LEC will need lesser efforts as needed for changing from HEC to MEC. This is empirically established by looking at the trend of behavior adoption in simulation as at the end of year 1 (from $t=0$ months to $t=12$ months); the LEC occupants have increased by $40 \%$ as opposed to a mere decrease of $17.4 \%$ in HEC occupants and $22 \%$ in MEC occupants, as shown in Table 10. It can be seen that at this stage that the conversion rate of MEC is better than the HEC. Though it is assumed that the change of occupant behavior will not be progressive, such that HEC may convert into MEC and then into LEC or directly into LEC, at the end of year 1 the energy saving will be quite small due to lesser conversion of HEC occupants who account for massive energy usage. This lack of willingness to change the behavior by HEC occupants as conveniently as that showed by the MEC occupants is partly based on the fact that the 'information deficit' model, based on which most of the information-intensive public education campaigns are based on Owens and Driffill [102], which assumes that increasing knowledge and awareness causes a positive change in energy usage behavior [103]. However, the evidence on behavior modification due to increased knowledge and attitude change suggests that such an effect is weak and short-lived [104]. The situation exacerbates in the face of generic and nonspecific information, rather than tailored information [105]. This implies that increase knowledge and awareness do not necessarily cause behavior modification, because knowledge is not a motivator for engagement in the desired behavior. However, a lack of knowledge and awareness might be a barrier [106]. Additionally, changing old habits is difficult when the motivation is not too high. Occupants typically do not have a direct financial interest in energy 
saving. Even among those who are motivated to conserve energy for non-financial reasons, not paying for their energy usage also means that occupants are not prepared to consider the energy used for workplace behaviors and have a little context for how much they have used compared to previous usage [107]. Finally, if someone has a higher usage tendency, it will not be quick and easy for them to improve their behavior.

However, consistency is the key. After constant exposure to energy-saving habits and awareness campaigns, a significant positive change is witnessed in the form of a $53 \%$ reduction in HEC occupants at the end of year 2 (from $t=13$ months to $t=24$ months) and $56 \%$ reduction at the end of year 3 (from $t=25$ months to $t=36$ months). The effect of constant exposure is also evident in MEC in the form of a dramatic reduction of $57 \%$ at the end of year 3 . This is a major achievement that justifies the investment in energy-saving interventions and financial incentives since monetary motivations drive energy-saving behavior [108]. So since the office occupants do not typically pay their bills [107], they can be motivated by chances of winning prizes [109].

The table further shows the energy consumed by occupants in each category calculated with the help of usage rates.

Table 10. The difference in energy usage before and after simulations.

\begin{tabular}{|c|c|c|c|c|c|c|c|c|c|}
\hline \multirow{2}{*}{$\begin{array}{c}\text { Occupant } \\
\text { Category }\end{array}$} & \multirow{2}{*}{$\begin{array}{c}\begin{array}{c}\text { Per Capita Usage/ } \\
\text { Year (kWh) }\end{array} \\
1524.4\end{array}$} & \multicolumn{2}{|c|}{$t=\underset{(\mathrm{kWh})}{0 \text { Months }}$} & \multicolumn{2}{|c|}{$t=\underset{(\mathrm{kWh})}{12 \text { Months }}$} & \multicolumn{2}{|c|}{$t=24$ Months } & \multicolumn{2}{|c|}{$\begin{array}{c}t=36 \text { Months } \\
(\mathrm{kWh})\end{array}$} \\
\hline & & 24 & $36,585.6$ & 40 & 60,976 & 55 & 83,842 & 81 & $123,476.4$ \\
\hline MEC & 2169 & 54 & 117,126 & 42 & 91,098 & 37 & 80,253 & 16 & 34704 \\
\hline HEC & 3308.8 & 23 & $76,102.4$ & 19 & $62,867.2$ & 9 & $29,779.2$ & 4 & $13,235.2$ \\
\hline \multicolumn{2}{|r|}{ Total } & \multicolumn{2}{|c|}{229,814} & \multicolumn{2}{|c|}{$214,941.2$} & \multicolumn{2}{|c|}{$193,874.2$} & \multicolumn{2}{|c|}{$171,415.6$} \\
\hline \multicolumn{4}{|c|}{ Annual savings } & \multicolumn{2}{|c|}{$6.5 \%$} & \multicolumn{2}{|c|}{$9.8 \%$} & \multicolumn{2}{|c|}{$11.6 \%$} \\
\hline \multicolumn{4}{|c|}{ Cumulative Savings } & \multicolumn{2}{|c|}{$6.5 \%$} & \multicolumn{2}{|c|}{$16.3 \%$} & \multicolumn{2}{|c|}{$27.9 \%$} \\
\hline
\end{tabular}

The impact of this behavior modification on energy usage is quantified through the number of occupants and the usage rates obtained from Table 9. At the end of year $1(t=12)$, the total energy saving is $6.5 \%$. Similarly, at $t=24$ and $t=36$, simulated energy savings are $16.3 \%$ and $27.9 \%$, respectively, highlighting that energy saved in year 1 is $6.5 \%$, year 2 is $9.8 \%$, and year 3 is $11.6 \%$. Hence, there is an increasing trend in total energy saving per year. The difference between the 1st and the 2nd year is substantial and continues to grow throughout the simulation period. At the end of year 1, the first energy event is organized causing a decrease in the number of HEC and MEC occupants and an increase in LEC occupants. The increasing number of LEC occupants is the sign of positive change in behavior that causes a reduction in total energy usage. At the end of the simulation, a very large number of occupants are converted to LEC, and only a few HEC occupants are left. Hence at this stage, $27.9 \%$ cumulative energy savings are realized. Referring to Table 4 , the average energy gap due to buildings is $15.5 \%$. Thus, by only changing the behavior of occupants by employing the above-mentioned techniques, the average electricity saving of $9.3 \%$ can be achieved every year. Interestingly, this saving potential falls well within the ranges reported by several other studies [110-114]. This $9.3 \%$ saving, when generalized to the level of an entire country, presents stimulating opportunities. For example, in Pakistan, all the sectors combined consumed a total of 110,890.13 GWh in 2017-2018 [115]. A mere 9.3\% saving will result in a saving of 1177.258 MW which is almost double of generation licenses, with a cumulative installed capacity of $652.54 \mathrm{MW}$, issued in 2018-2019. This number is close to the installed capacity of wind power in the country (1235 MW) [116]. Since the overall energy usage in Pakistan is lower than the developed countries, this $9.3 \%$ saving can mean a saving of 2463.6 MW in the Australian energy context for the year 2017-2018 [117] or 119,165.5 MW in the USA energy context for the same year [118].

Though these figures show the significance of saving potential, still, in order to statistically validate these claims, analysis is performed on the estimated usage. It is hypothesized that before and 
after the behavior modification, usage will be significantly different. Single-factor ANOVA is applied to the pre- and post-modification usage figures. Initially, using a $95 \%$ confidence level, the p-value comes out to be 0.075 which is outside the significant range. However, at a $90 \%$ confidence level, the p-value comes within a significant range. Additionally, the F-statistic at this level is significant since $\mathrm{F}_{\text {critic }}<\mathrm{F}(3.776<4.6)$. It is opportune to mention that the already lower per capita usage of Pakistan has greatly influenced the results and the test has failed at $95 \%$. In case the same study is repeated in countries with higher per capita energy usage, such as Australia or the United States, it is expected that significant findings will be achieved at a higher confidence level.

\section{Conclusions}

Energy-efficient buildings have a long way to go in fulfilling their design energy performance targets. The literature highlights the gap between design and actual energy usage. Other than physical and technical reasons, occupant behavior which is repeatable and has a temporal extent, as well as locus, is one promising area for controlling this gap. By analyzing the results of surveyed data, a normal distribution of occupant behavior is obtained in which most of the occupants are placed in the MEC category which points to their average awareness regarding energy conservation. This awareness comes in handy when influencing their behavior for low energy usage as there are more chances to convert MEC to LEC if training and informatory sessions are arranged. The number of LEC and HEC occupants is almost equal as per initial findings, which implies that LEC occupants are saving a significant amount of energy. However, the difference between LEC and MEC occupants is significantly lower than that between MEC and HEC occupants highlighting that HEC occupants consume more energy, which nullifies the savings of LEC occupants.

Fortunately, HEC occupants can be converted with significant effort into other categories. Their interaction with MEC or LEC occupants seems to inspire their usage behavior. Research shows that if the behavior change occurs by imposing certain conditions, it may last only for 3-10 weeks while the change due to their own awareness lasts for a longer time [89]. Accordingly, energy events, mutual interaction and energy-saving discussions of occupants and advertisements are found to be more useful instead of feedback and other imposed techniques. By simulating behavior modification techniques, it is found that $25.4 \%$ of energy can be saved in 3 years. It means that at a very little cost of employing the modification techniques, an average $8.5 \%$ of energy can be saved annually. This is better than technical changes in buildings, which may save more energy but at a very high capital cost and low rate of return.

This study reports the findings of simulating consumer behavior in an office building environment and leads to further possible work in energy savings through behavioral training of the occupants. It is expected that integrating the proposed simulation model with commercially available energy estimation programs could significantly improve the energy estimates. As a result, it will help to overcome the existing limitations of the software used in the industry. The model can be used by the facility management team to enhance the energy-saving endeavors. Finally, it can also be used as a decision support system that evaluates several methods of changing behavior such as seminars on energy conservation, peer-to-peer influence, and feedback tools, and helps the designers and owners to choose the best alternative for reducing energy demand. As a follow up to the current study and for validating the results using real-life case studies, the researchers are discussing with the building managers about implementing such behavior-changing energy events and training for the specific building types chosen in Pakistan. Subsequently, the follow-up studies will report the findings of these energy events and help validate the model based on real-life events and data collected.

A limitation of the current study is the availability of data for generalizing the model to all types of buildings and, as a result, the study is limited to commercial office buildings only. The study was conducted in Pakistan, which is a developing country and has data banking issues. Additionally, the number of case projects was limited to three due to the lack of energy-efficient buildings in Pakistan. The same study, if repeated in a developed country, can yield a more precise and generalized model that 
can be adopted by the planners and decision-makers in developing energy-saving strategies. This can also aid in building retrofitting and extension decisions when working on the existing building stock to save more energy and achieve sustainability goals. The research is further constrained by the lack of availability of commercial software for in-depth analysis. However, where this lack of commercial software is a challenge for the current study, it provides a potential opportunity for developers to invest in, at the same time. In the future, it is expected that commercial software can be launched to help facilitate the decision-makers in key energy-saving decisions by exploring occupant behavior. In this aspect, the suggestions by Hong et al. [119] for the quantification of the economic-environmental values through a life cycle cost analysis and life cycle assessment analysis coupled with thermal comfort and thermal energy usage assessed through the tools such as EnergyPlus ${ }^{\mathrm{TM}}$ can help the industry develop a more sustainable and all-inclusive approach towards energy optimizations and savings. Another limitation of this study is the exclusion of heating load mainly because of the predominant contextual requirement of a warm dry region. It is obvious that the internal heat gains from appliances would be reduced and so the cooling demand would be due to the promulgation of LEC behavior. This implies that reduced energy use would not only directly affect the total energy use but also indirectly, by reducing cooling demand. Future research may consider this cyclic reinforcing effect due to behavior modification. The last limitation of this study is the use of published inputs of behavior influencing parameters. This calls for detailed and experimental future studies that can inspect and validate the behavioral implications of energy consumers under the local socio-cultural and techno-economic conditions.

Author Contributions: All authors have read and agreed to the published version of the manuscript. Further, all authors have contributed equally to the paper.

Funding: This research received no external funding.

Conflicts of Interest: The authors declare no conflict of interest.

\section{Appendix A The Questionnaire}

\section{A. Personal information:}

1. Gender:

o Male

o Female

2. Age: o 20 years or under

o 21-30 years

o 31-40 years

o $\quad 41-50$ years

3. The level of qualification you have?

o School/High School o Post-graduation

o 51-60 years

o Above 60

4. Where is your workspace located? Specify floor number:

5. Do you have a permanent workspace in your building?

o Graduation

o Doctoral

6. How long have you been working at your present workspace? Years:

Months:

7. Which of the following best describes your personal workspace or the type of space you usually work at?

o Enclosed office, private

o Enclosed office, shared with other people

o Cubicles with partition wall 5' or higher

o Cubicles with partition wall lower than $5^{\prime}$

8. How much time you spend at your work place daily?

o 1-3 hours o 3-6 hours o 6-9 hours o Or more 


\section{B. Equipment:}

1. Which of the following electronics, including personally owned, are in your workspace? Check all that apply.

o Laptop o desktop computer o desk phone o fan

o space heater o smart phone docking station o electric clock o desk lamp

o other (please describe):

2. How much time you work on your computer daily?

$\begin{array}{llll}\text { o 1-3 hours o 3-6 hours 6-9 hours o Or more } & \end{array}$

3. What you usually do with your computer when you leave your office for a short break or for a short meeting?

o Shut down o Put it on sleep mode

o Put it on hibernate mode o Just turn off the LCD/Monitor

4. What do you do with your computer when you leave your office for home?

o Shut down o Put it on sleep mode

o Put it on hibernate mode o Just turn off the LCD/Monitor

5. If you have a personal printer at your work place, then you:

o Switch it on when you need it o Switch it off when you remember

o Switch it off right after use o Or it remains switched on every time

6. If you have a personal scanner at your work place, then you:

o Switch it on when you need it o Switch it off when you remember

o Switch it off right after use o Or it remains switched on every time

7. If you have a fan at your work place then for approximately how much time you turn it on in a day?

o 1-3 hours o 3-6 hours o 6-9 hours o Or more

\section{Day light}

1. Within the proximity of 15 feet, what do you have for natural lighting? Check all that apply.

o Window o Ventilator o Skylight o Nothing

2. Please indicate why you are dissatisfied with visual comfort by checking all the reasons that apply:

o Not enough daylight most of the day o Too much daylight most of the day

o Not enough overhead light in my workspace o Too much overhead light in my workspace

o Not enough overhead light in the office overall o Too much overhead light in the office overall

o No task lighting

o Daylight glare from windows o Reflections in/glare on the computer screen o Other (please describe)

3. If you have windows in your office, for how much time do you use day light approximately?

o 1-2 hours o 2-4 hours o 4-6 hours o Or more

4. If you feel discomfort from day light then what do you do?

o Adjust the blinds/shades o Complain your manager/supervisor

o Talk with others in your group about the problem o Change your position in your workspace

o Other please specify:

5. How often you change the orientation of the blinds to let day light in?

o Regularly o Often o Never o Can't adjust

6. In summers for how long you use daylight without feeling hot?
o $1-2$ hours
o 2-4 hours
o 4-6 hours
o Or more 
D. Artificial light:

1. If you have an individual office, how many lights do you have in your room?

o 1-2 lights o 2-3 lights o $3-4$ lights o Or more

2. How many of the lights you usually switch on while you are in your office?

o 1-2 lights o 2-3 lights o 3-4 lights o Or more

3. If you have a desk lamp at your work place, for how long you use it?

o 1-2 lights o 2-3 lights o 3-4 lights o Or more

4. If you have a shared office, then can you control its lights?

o Yes o No

If you can control the lights then you turn them off when you don't need artificial light?
o Very often
o Often
o Not often
o Never

5. Do you switch lights off when you leave office for a break/meeting?

o Yes o No o No need because they are automatic

6. Do you switch lights when you leave office for home?

o Yes o No o No need because they are automatic

\section{E. HVAC}

1. What type of HVAC system do you have in your office?

o Individual unit o Centrally controlled system

2. If you have an individual unit, what do you do when you leave office for a break/meeting?

o Switch it off o Put it on Economy Mode

o Set its temperature between $24-26^{\circ} \mathrm{C} \quad$ o Leave office without doing anything

3. If you have an individual unit, what do you do when you leave office for home?

o Switch it off o Leave office without doing anything

o Timer is set which switch it off automatically

4. If centrally controlled system is installed in your office then is there any control panel to manage your surrounding temperature?

o Yes

o No

5. Please indicate why you are dissatisfied with the temperature of your workspace by checking all the reasons that apply:

o Too hot much of the time o Too hot in the summer o Too hot in the winter

o Too cold much of the time o Too cold in the summer o Too cold in the winter

o Other (please describe):

6. If the temperature of your work place is very cold then what do you usually do?

o Adjust thermostat

o Complain your Supervisor

o Change your location o Open or close the window shades o Complain your Building manager o Talk with others in your group 


\section{F. Energy Efficiency:}

1. How well you are aware of energy efficiency and sustainability?

$$
\begin{array}{lllll}
1 & 2 & 3 & 4 & 5
\end{array} \text { (Not well informed to Very well informed) }
$$

2. How well informed do you feel about using the energy saving design features in your building?

$$
\begin{array}{lllll}
1 & 2 & 3 & 4 & 5 \text { (Not well informed to Very well informed) }
\end{array}
$$

3. Have you attended any course, workshop, training session, etc. about energy efficiency and sustainability? o Yes o No

If yes, how well informed do you feel about energy efficiency and conservation after taking the course/seminar/workshop? $\begin{array}{lllll}1 & 2 & 3 & 4 & 5\end{array}$ (Not well to Very well)

4. How would you describe your approach to reducing energy in your building? Check all that apply.

o Follow policies/practices in energy conservation workshop/training o I act as role model for others

o I have accepted/taken on a formal lead role in the group/department/floor

o Other (please describe) :

5. Have you or any members in your group been recognized by your management or chain of command for efficient energy use?

o Yes o No o Don't know

6. How many people you know who adopt energy saving habits?

o 1-4 persons o 4-8 persons o 8-12 persons or more

\section{References}

1. Lee, Y.S.; Malkawi, A. Simulating human behavior: An agent-based modeling approach. In Proceedings of the 13th IBPSA Conference, Chambéry, France, 26-28 August 2013.

2. Azar, E.; Menassa, C.C. Agent-based modeling of occupants and their impact on energy use in commercial buildings. J. Comput. Civ. Eng. 2011, 26, 506-518. [CrossRef]

3. Zavvar Sabegh, M.R.; Bingham, C. Model predictive control with binary quadratic programming for the scheduled operation of domestic refrigerators. Energies 2019, 12, 4649. [CrossRef]

4. Wang, C.C.; Sepasgozar, S.M.; Wang, M.; Ning, X. Green performance evaluation system for energy-efficiency-based planning for construction site layout. Energies 2019, 12, 4620. [CrossRef]

5. Tang, Y.; Liu, Z.; Li, L. Performance comparison of a distributed energy system under different control strategies with a conventional energy system. Energies 2019, 12, 4613. [CrossRef]

6. Calama-González, C.M.; León-Rodríguez, Á.L.; Suárez, R. Indoor air quality assessment: Comparison of ventilation scenarios for retrofitting classrooms in a hot climate. Energies 2019, 12, 4607. [CrossRef]

7. UNEP. Buildings can Play Key Role in Combating Climate Change. United Nations Energy Program. Available online: http://www.unep.org/Documents.Multilingual/Default.asp? DocumentID=502\&ArticleID= 5545\&l=en (accessed on 10 March 2017).

8. Jeon, J.; Lee, S.; Hong, D.; Kim, Y. Performance evaluation and modeling of a hybrid cooling system combining a screw water chiller with a ground source heat pump in a building. Energy 2010, 35, 2006-2012. [CrossRef]

9. Energy Information Administration; EIA: Washington, DC, USA, 2010.

10. Wong, J.; Li, H.; Wang, S. Intelligent building research: A review. Autom. Constr. 2005, 14, 143-159. [CrossRef]

11. Asif, M. Sustainable energy options for Pakistan. Renew. Sustain. Energy Rev. 2009, 13, 903-909. [CrossRef]

12. Farooqui, S.Z. Prospects of renewables penetration in the energy mix of Pakistan. Renew. Sustain. Energy Rev. 2014, 29, 693-700. [CrossRef]

13. Khalil, H.B.; Zaidi, S.J.H. Energy crisis and potential of solar energy in Pakistan. Renew. Sustain. Energy Rev. 2014, 31, 194-201. [CrossRef]

14. Shah, S.A.A.; Solangi, Y.A. A sustainable solution for electricity crisis in Pakistan: Opportunities, barriers, and policy implications for 100\% renewable energy. Environ. Sci. Pollut. Res. 2019, 26, 29687-29703. [CrossRef]

15. Azeem, S.; Naeem, M.A.; Waheed, A.; Thaheem, M.J. Examining barriers and measures to promote the adoption of green building practices in Pakistan. Smart Sustain. Built Environ. 2017. [CrossRef] 
16. De Wilde, P. The gap between predicted and measured energy performance of buildings: A framework for investigation. Autom. Constr. 2014, 41, 40-49. [CrossRef]

17. Demanuele, C.; Tweddell, T.; Davies, M. Bridging the gap between predicted and actual energy performance in schools. In Proceedings of the World Renewable Energy Congress XI, Abu Dhabi, UAE, 25-30 September 2010.

18. Menezes, A.C.; Cripps, A.; Bouchlaghem, D.; Buswell, R. Predicted vs. actual energy performance of non-domestic buildings: Using post-occupancy evaluation data to reduce the performance gap. Appl. Energy 2012, 97, 355-364.

19. Bordass, B. Energy performance of non-domestic buildings: Closing the credibility gap. In Proceedings of the 2004 Improving Energy Efficiency of Commercial Buildings Conference, Frankfurt, Germany, 19-20 Apirl 2004.

20. Bordass, B.; Cohen, R.; Standeven, M.; Leaman, A. Assessing building performance in use 3: Energy performance of the Probe buildings. Build. Res. Inf. 2001, 29, 114-128. [CrossRef]

21. Ullah, F.; Sepasgozar, S.M.; Wang, C. A systematic review of smart real estate technology: Drivers of, and barriers to, the use of digital disruptive technologies and online platforms. Sustainability 2018, 10, 3142. [CrossRef]

22. Ullah, F.; Samad Sepasgozar, P.; Ali, T.H. Real estate stakeholders technology acceptance model (RESTAM): User-focused big9 disruptive technologies for smart real estate management. In Proceedings of the 2nd International Conference on Sustainable Development in Civil Engineering (ICSDC 2019), Jamshoro, Pakistan, 25-27 October 2019.

23. Ullah, F.; Sepasgozar Samad, M.; Siddiqui, S. An investigation of real estate technology utilization in technologically advanced marketplace. In Proceedings of the the 9th International Civil Engineering Congress (ICEC-2017), "Striving Towards Resilient Built Environment”, Karachi, Pakistan, 22-23 December 2017.

24. Ullah, F.; Shinetogtokh, T.; Samad Sepasgozar, P.; Ali, T.H. Investigation of the users' interaction with online real estate platforms in Australia. In Proceedings of the 2nd International Conference on Sustainable Development in Civil Engineering (ICSDC 2019), Jamshoro, Pakistan, 25-27 October 2019.

25. D'agostino, D.; Zangheri, P.; Castellazzi, L. Towards nearly zero energy buildings in Europe: A focus on retrofit in non-residential buildings. Energies 2017, 10, 117. [CrossRef]

26. Noubissie Tientcheu, S.I.; Chowdhury, S.P.; Olwal, T.O. Intelligent energy management strategy for automated office buildings. Energies 2019, 12, 4326. [CrossRef]

27. Mjörnell, K.; Johansson, D.; Bagge, H. The effect of high occupancy density on IAQ, moisture conditions and energy use in apartments. Energies 2019, 12, 4454. [CrossRef]

28. Kaminska, A. Impact of heating control strategy and occupant behavior on the energy consumption in a building with natural ventilation in Poland. Energies 2019, 12, 4304. [CrossRef]

29. Bourgeois, D.; Reinhart, C.; Macdonald, I. Adding advanced behavioural models in whole building energy simulation: A study on the total energy impact of manual and automated lighting control. Energy Build. 2006, 38, 814-823. [CrossRef]

30. Staats, H.; Leeuwen, E.; Wit, A. A longitudinal study of informational interventions to save energy in an office building. J. Appl. Behav. Anal. 2000, 33, 101-104. [CrossRef] [PubMed]

31. EnergyPlus. Input/Output Reference: The Encyclopedic Reference to EnergyPlus Input and Output. The Board of Trustees of the Univ. of Illinois and the Regents of the Univ. of California through the Ernest Orlando Lawrence Berkeley National Laboratory. Available online: https://energyplus.net/sites/default/files/ pdfs/pdfs_v8.3.0/InputOutputReference.pdf (accessed on 12 March 2020).

32. Introductory Tutorial, version 3.63; eQuest: Camarillo, CA, USA, 2009.

33. Clevenger, C.M.; Haymaker, J. The impact of the building occupant on energy modeling simulations. In Proceedings of the Joint International Conference on Computing and Decision Making in Civil and Building Engineering, Montreal, OC, Canada, 16 June 2006.

34. Hoes, P.; Hensen, J.; Loomans, M.; De Vries, B.; Bourgeois, D. User behavior in whole building simulation. Energy Build. 2009, 41, 295-302. [CrossRef]

35. Yu, Z.; Fung, B.C.; Haghighat, F.; Yoshino, H.; Morofsky, E. A systematic procedure to study the influence of occupant behavior on building energy consumption. Energy Build. 2011, 43, 1409-1417. [CrossRef]

36. D'Oca, S.; Hong, T.; Langevin, J. The human dimensions of energy use in buildings: A review. Renew. Sustain. Energy Rev. 2018, 81, 731-742. [CrossRef] 
37. Langevin, J.; Wen, J.; Gurian, P.L. Including occupants in building performance simulation: Integration of an agent-based occupant behavior algorithm with Energy Plus. In Proceedings of the ASHRAE/IBPSAUSA Buidling Simulation Conference, Atlanta, GA, USA, 10-12 September 2014.

38. Al-janabi, A.; Kavgic, M.; Mohammadzadeh, A.; Azzouz, A. Comparison of EnergyPlus and IES to model a complex university building using three scenarios: Free-floating, ideal air load system, and detailed. J. Build. Eng. 2019, 22, 262-280. [CrossRef]

39. Lam, K.P.; Zhao, J.; Ydstie, E.B.; Wirick, J.; Qi, M.; Park, J.H. An EnergyPlus whole building energy model calibration method for office buildings using occupant behavior data mining and empirical data. In Proceedings of the ASHRAE/IBPSAUSA Buidling Simulation Conference, Atlanta, GA, USA, 10-12 September 2014; pp. 160-167.

40. Turner, C.; Frankel, M.; Council, U.G.B. Energy performance of LEED for new construction buildings. New Build. Inst. 2008, 4, 1-42.

41. Almeida, N.; Sousa, V.; Alves Dias, L.; Branco, F. A framework for combining risk-management and performance-based building approaches. Build. Res. Inf. 2010, 38, 157-174. [CrossRef]

42. Koziolek, H. Performance evaluation of component-based software systems: A survey. Perform. Eval. 2010, 67, 634-658. [CrossRef]

43. Zhang, X.; Gao, H. Optimal performance-based building facility management. Comput. Aided Civ. Infrastruct. Eng. 2010, 25, 269-284. [CrossRef]

44. Nguyen, A.T.; Singh, M.K.; Reiter, S. An adaptive thermal comfort model for hot humid South-East Asia. Build. Environ. 2012, 56, 291-300. [CrossRef]

45. Manu, S.; Shukla, Y.; Rawal, R.; Thomas, L.E.; De Dear, R. Field studies of thermal comfort across multiple climate zones for the subcontinent: India model for adaptive comfort (IMAC). Build. Environ. 2016, 98, 55-70. [CrossRef]

46. Oberkampf, W.L.; Roy, C.J. Verification and Validation in Scientific Computing; Cambridge University Press: Cambridge, UK, 2010.

47. Clarke, J. Energy Simulation in Building Design, 2002; Butterworth-Heinemann: Oxford, UK, 2002; ISBN 0-750-65082-6.

48. Norford, L.; Socolow, R.; Hsieh, E.; Spadaro, G. Two-to-one discrepancy between measured and predicted performance of a 'low-energy'office building: Insights from a reconciliation based on the DOE-2 model. Energy Build. 1994, 21, 121-131. [CrossRef]

49. Kim, S.; Song, Y.; Sung, Y.; Seo, D. Development of a consecutive occupancy estimation framework for improving the energy demand prediction performance of building energy modeling tools. Energies 2019, 12, 433. [CrossRef]

50. Gercek, M.; Arsan, Z.D. Energy and environmental performance based decision support process for early design stages of residential buildings under climate change. Sustain. Cit. Soc. 2019, 48, 101580. [CrossRef]

51. Mirabella, N.; Roeck, M.; Ruschi Mendes Saade, M.; Spirinckx, C.; Bosmans, M.; Allacker, K.; Passer, A. Strategies to improve the energy performance of buildings: A review of their life cycle impact. Buildings 2018, 8, 105. [CrossRef]

52. Sanguinetti, P. Integrated Performance Framework to Guide Façade Retrofit; Georgia Institute of Technology: Atlanta, GA, USA, 2012.

53. Hub, Z.C. Carbon Compliance for Tomorrow's new Homes: A Review of the Modelling Tool and Assumptions, Topic 4-Closing the Gap Between Designed and Built Performance [online]. London: Zero Carbon Hub and NHBC Foundation; NHBC Foundation: Milton Keynes, UK, 2010.

54. Newsham, G.R.; Benjamin, J.B.; Chantal, A.; Alexandra, J.L.T.; Jennifer, A.V.; Sandra, M.; Anca, D.G.; Bradford, N.G.; Iain, A.M.; Gregory, J.B. Do 'green'buildings have better indoor environments? New evidence. Build. Res. Inf. 2013, 41, 415-434. [CrossRef]

55. Erickson, V.L.; Lin, Y.; Kamthe, A.; Brahme, R.; Surana, A.; Cerpa, A.E.; Sohn, M.D.; Narayanan, S. Energy efficient building environment control strategies using real-time occupancy measurements. In Proceedings of the First ACM Workshop on Embedded Sensing Systems for Energy-Efficiency in Buildings, Berkeley, CA, USA, November 2009.

56. Bell, M.; Wingfield, J.; Miles-Shenton, D.; Seavers, J. Low carbon housing: Lessons from Elm Tree Mews; Joseph Rowntree Foundation: York, UK, 2010. 
57. Haldi, F.; Robinson, D. On the behaviour and adaptation of office occupants. Build. Environ. 2008, 43, 2163-2177. [CrossRef]

58. Korjenic, A.; Bednar, T. Validation and evaluation of total energy use in office buildings: A case study. Autom. Constr. 2012, 23, 64-70. [CrossRef]

59. Fanger, P.O.; Toftum, J. Extension of the PMV model to non-air-conditioned buildings in warm climates. Energy Build. 2002, 34, 533-536. [CrossRef]

60. Nicol, J.F.; Humphreys, M.A. Thermal comfort as part of a self-regulating system. Build. Res. Pract. 1973, 1, 174-179. [CrossRef]

61. Ajzen, I. The theory of planned behavior. Organ. Behav. Hum. Decis. Process. 1991, 50, 179-211. [CrossRef]

62. Wang, Z.; Zhang, B.; Li, G. Determinants of energy-saving behavioral intention among residents in Beijing: Extending the theory of planned behavior. J. Renew. Sustain. Energy 2014, 6, 053127. [CrossRef]

63. Chan, L.; Bishop, B. A moral basis for recycling: Extending the theory of planned behaviour. J. Environ. Psychol. 2013, 36, 96-102. [CrossRef]

64. Gao, L.; Wang, S.; Li, J.; Li, H. Application of the extended theory of planned behavior to understand individual's energy saving behavior in workplaces. Resour. Conserv. Recycl. 2017, 127, 107-113. [CrossRef]

65. Li, G.; Liu, W.; Wang, Z.; Liu, M. An empirical examination of energy consumption, behavioral intention, and situational factors: Evidence from Beijing. Ann. Oper. Res. 2017, 255, 507-524. [CrossRef]

66. Webber, C.A.; Roberson, J.A.; McWhinney, M.C.; Brown, R.E.; Pinckard, M.J.; Busch, J.F. After-hours power status of office equipment in the USA. Energy 2006, 31, 2823-2838. [CrossRef]

67. Sanchez, M.; Webber, C.; Brown, R.; Busch, J.; Pinckard, M.; Roberson, J. Space Heaters, Computers, Cell Phone Chargers: How Plugged in are Commercial Buildings? Lawrence Berkeley National Laboratory: Berkeley, CA, USA, 2007.

68. Wang, D.; Federspiel, C.C.; Rubinstein, F. Modeling occupancy in single person offices. Energy Build. 2005, 37, 121-126. [CrossRef]

69. Jackson, T. Motivating Sustainable Consumption: A Review of Evidence on Consumer Behaviour and Behavioural Change: A Report to the Sustainable Development Research Network; University of Surrey: Guildford, UK, 2005.

70. Peschiera, G.; Taylor, J.E.; Siegel, J.A. Response-relapse patterns of building occupant electricity consumption following exposure to personal, contextualized and occupant peer network utilization data. Energy Build. 2010, 42, 1329-1336. [CrossRef]

71. Zangheri, P.; Serrenho, T.; Bertoldi, P. Energy savings from feedback systems: A meta-studies' review. Energies 2019, 12, 3788. [CrossRef]

72. Wood, G.; Newborough, M. Dynamic energy-consumption indicators for domestic appliances: Environment, behaviour and design. Energy Build. 2003, 35, 821-841. [CrossRef]

73. Bellomo, N.; Piccoli, B.; Tosin, A. Modeling crowd dynamics from a complex system viewpoint. Math. Model. Methods Appl. Sci. 2012, 22, 1230004. [CrossRef]

74. Bonabeau, E. Agent-based modeling: Methods and techniques for simulating human systems. Proc. Natl. Acad. Sci. USA 2002, 99, 7280-7287. [CrossRef] [PubMed]

75. Sweeney, L.B.; Sterman, J.D. Thinking about systems: Student and teacher conceptions of natural and social systems. Syst. Dyn. Rev. 2007, 23, 285-311. [CrossRef]

76. Ullah, F.; Thaheem, M.J.; Sepasgozar, S.M.; Forcada, N. System dynamics model to determine concession period of PPP infrastructure projects: Overarching effects of critical success factors. J. Legal Aff. Disput. Resolut. Eng. Constr. 2018, 10, 04518022. [CrossRef]

77. Ullah, F.; Sepasgozar, S.M. A study of information technology adoption for real-estate management: A system dynamic model. Innov. Prod. Constr. Transf. Constr. Through Emerg. Technol. 2019, 469-484. [CrossRef]

78. Ullah, F.; Thaheem, M.J.; Siddiqui, S.Q.; Khurshid, M.B. Influence of Six Sigma on project success in construction industry of Pakistan. TQM J. 2017, 29, 276-309. [CrossRef]

79. Axtell, R. Why agents? on the varied motivations for agent computing in the social sciences; Center on Social and Economic Dynamics Working Paper No. 17; Center on Social and Economic Dynamics: Washington, DC, USA, 2000.

80. Dikba, A.; Dikbas, A. eWork and eBusiness in Architecture, Engineering and Construction; Taylor \& Francis: Abingdon, UK, 2004.

81. Macal, C.M.; North, M.J. Tutorial on agent-based modeling and simulation. In Proceedings of the 37th Conference on Winter Simulation, Orlando, FL, USA, 4-14 December 2005. 
82. Li, Z.; Heo, Y.; Augenbroe, G. HVAC design informed by organizational simulation. In Proceedings of the Eleventh International IBPSA Conference, Glasgow, Scotland, 27-30 July 2009.

83. Guthridge, G. Understanding consumer preferences in energy efficiency: Accenture end-consumer observatory on electricity management; Accenture: Dublin, Ireland, 2010.

84. Davis, J.A.; Nutter, D.W. Occupancy diversity factors for common university building types. Energy Build. 2010, 42, 1543-1551. [CrossRef]

85. Dwyer, T. Knowledge is Power: Benchmarking and prediction of building energy consumption. Build. Serv. Eng. Res. Technol. 2013, 34, 5-7. [CrossRef]

86. Lane, D.C. Modeling for learning organizations. J. Operat. Res. Soc. 1995, 46, 793-795.

87. Dillman, D.A. Mail and Internet Surveys: The Tailored Design Method; Wiley: New York, NY, USA, 2000.

88. Borshchev, A.; Filippov, A. From system dynamics and discrete event to practical agent based modeling: Reasons, techniques, tools. In Proceedings of the 22nd International Conference of the System Dynamics Society, Oxford, UK, 25-29 July 2004.

89. De Young, R. Changing behavior and making it stick: The conceptualization and management of conservation behavior. Environ. Behav. 1993, 25, 485-505. [CrossRef]

90. Bhatt, R.; Chaoji, V.; Parekh, R. Predicting product adoption in large-scale social networks. In Proceedings of the 19th ACM International Conference on Information and Knowledge Management, 26-30October 2010.

91. De Chiara, J.; Panero, J.; Zelnik, M. Time-Saver Standards for Interior Design and Space Planning; McGraw-Hill Companies: New York, NY, USA, 1991.

92. PEPCO. Available online: www.pepcopakistan.com (accessed on 12 March 2020).

93. American Society of Heating Refrigerating; Air-Conditioning Engineers (ASHRAE). Energy Standard for Buildings Except Low-Rise Residential Buildings, ANSI/ASHRAE/IESNA Standard 90.1; ASHRAE: Atlanta, GA, USA, 2007.

94. Masoso, O.; Grobler, L.J. The dark side of occupants' behaviour on building energy use. Energy Build. 2010, 42, 173-177. [CrossRef]

95. Plympton, P.; Conway, S.; Epstein, K. Daylighting in Schools: Improving Student Performance and Health at a Price Schools Can Afford. In Proceedings of the American Solar Energy Society Conference Madison, Wisconsin, WI, USA, 16 June 2000.

96. Doulos, L.; Tsangrassoulis, A.; Topalis, F. Quantifying energy savings in daylight responsive systems: The role of dimming electronic ballasts. Energy Build. 2008, 40, 36-50. [CrossRef]

97. Li, D.H.; Lam, T.N.; Wong, S. Lighting and energy performance for an office using high frequency dimming controls. Energy Convers. Manag. 2006, 47, 1133-1145. [CrossRef]

98. Onaygıl, S.; Güler, Ö. Determination of the energy saving by daylight responsive lighting control systems with an example from Istanbul. Build. Environ. 2003, 38, 973-977. [CrossRef]

99. Company, N.T.D. Power System Statistics 2017-2018. Available online: http://www.ntdc.com.pk/ntdc/ public/uploads/services/planning/power\%20system\%20statistics/pss\%2043rd\%20Edition.pdf (accessed on 21 December 2019).

100. Mundi, I. Electricity Consumption Per Capita-World. Available online: https://www.indexmundi.com/ map/?v=81000 (accessed on 21 December 2019).

101. WDI. Available online: http://data.worldbank.org/indicator/EG.USE.ELEC.KH.PC (accessed on 20 December 2019).

102. Owens, S.; Driffill, L. How to change attitudes and behaviours in the context of energy. Energy Policy 2008, 36, 4412-4418. [CrossRef]

103. Hesselink, L.X.; Chappin, E.J. Adoption of energy efficient technologies by households-Barriers, policies and agent-based modelling studies. Renew. Sustain. Energy Rev. 2019, 99, 29-41. [CrossRef]

104. Sweeney, J.C.; Kresling, J.; Webb, D.; Soutar, G.N.; Mazzarol, T. Energy saving behaviours: Development of a practice-based model. Energy Policy 2013, 61, 371-381. [CrossRef]

105. Lorenzoni, I.; Nicholson-Cole, S.; Whitmarsh, L. Barriers perceived to engaging with climate change among the UK public and their policy implications. Glob. Environ. Chang. 2007, 17, 445-459. [CrossRef]

106. Hafner, R.; Elmes, D.; Read, D.; White, M.P. Exploring the role of normative, financial and environmental information in promoting uptake of energy efficient technologies. J. Environ. Psychol. 2019, 63, 26-35. [CrossRef] 
107. Carrico, A.R.; Riemer, M. Motivating energy conservation in the workplace: An evaluation of the use of group-level feedback and peer education. J. Environ. Psychol. 2011, 31, 1-13. [CrossRef]

108. Fiorillo, D.; Sapio, A. Energy saving in Italy in the late 1990s: Which role for non-monetary motivations? Ecol. Econ. 2019, 165, 106386. [CrossRef]

109. Needleman, L.D.; Geller, E.S. Comparing interventions to motivate work-site collection of home-generated recyclables. Am. J. Community Psychol. 1992, 20, 775-785. [CrossRef]

110. Abrahamse, W.; Steg, L.; Vlek, C.; Rothengatter, T. The effect of tailored information, goal setting, and tailored feedback on household energy use, energy-related behaviors, and behavioral antecedents. J. Environ. Psychol. 2007, 27, 265-276. [CrossRef]

111. Ouyang, J.; Hokao, K. Energy-saving potential by improving occupants' behavior in urban residential sector in Hangzhou City, China. Energy Build. 2009, 41, 711-720. [CrossRef]

112. Faruqui, A.; Sergici, S.; Sharif, A. The impact of informational feedback on energy consumption-A survey of the experimental evidence. Energy 2010, 35, 1598-1608. [CrossRef]

113. Ueno, T.; Sano, F.; Saeki, O.; Tsuji, K. Effectiveness of an energy-consumption information system on energy savings in residential houses based on monitored data. Appl. Energy 2006, 83, 166-183. [CrossRef]

114. Fischer, C. Feedback on household electricity consumption: A tool for saving energy? Energy Effic. 2008, 1, 79-104. [CrossRef]

115. NEPRA. State of Industry Report 2018. Available online: https://www.nepra.org.pk/publications/State\% 20of\%20Industry\%20Reports/State\%20of\%20Industry\%20Report\%202018.pdf (accessed on 12 February 2020).

116. NEPRA; Annual Report 2018-19. Available online: https://www.nepra.org.pk/publications/Annual\% 20Reports/Annual\%20Report\%202018-19.pdf (accessed on 12 February 2020).

117. Energy, A. Australian Energy Update 2019. Available online: https://www.energy.gov.au/sites/default/files/ australian_energy_statistics_2019_energy_update_report_september.pdf (accessed on 12 February 2020).

118. Energy, U. USA Energy Facts 2018. Available online: https://www.eia.gov/energyexplained/us-energy-facts/ (accessed on 12 February 2020).

119. Hong, T.; Kim, J.; Lee, M. A multi-objective optimization model for determining the building design and occupant behaviors based on energy, economic, and environmental performance. Energy 2019, 17, 823-834. [CrossRef]

(C) 2020 by the authors. Licensee MDPI, Basel, Switzerland. This article is an open access article distributed under the terms and conditions of the Creative Commons Attribution (CC BY) license (http://creativecommons.org/licenses/by/4.0/). 